\title{
DEUTERIUM AND TRITIUM EXPERIMENTS ON TFTR
}

\author{
BY \\ J.D. STRACHAN, H. ADLER, C. BARNES, ET AL.
}

Invited talk presented at the 21st EPS Meeting of Plasma Physics Division, Montpellier, France, June 27-July 1, 1994.

Work supported by U.S. Department of Energy Contract DE-AC02-76CH0-3073

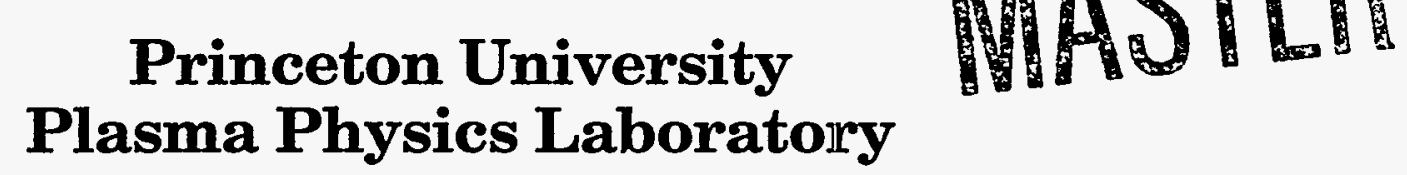

Distrieution of the 


\section{DISCLAIMER}

This report was prepared as an account of work sponsored by an agency of the United States Government. Neither the United States Government nor any agency thereof, nor any of their employees, make any warranty, express or implied, or assumes any legal liability or responsibility for the accuracy, completeness, or usefulness of any information, apparatus, product, or process disclosed, or represents that its use would not infringe privately owned rights. Reference herein to any specific commercial product, process, or service by trade name, trademark, manufacturer, or otherwise does not necessarily constitute or imply its endorsement, recommendation, or favoring by the United States Government or any agency thereof. The views and opinions of authors expressed herein do not necessarily state or reflect those of the United States Government or any agency thereof. 


\section{DISCLAIMER}

Portions of this document may be illegible in electronic image products. Images are produced from the best available original document. 


\title{
Deuterium and Tritium Experiments on TFTR
}

J.D. Strachan, H. Adler, Cris W. Barnes, ${ }^{1}$ S. Batha, ${ }^{2}$ M.G. Bell, R. Bell, M. Bitter, N.L. Bretz, R. Budny, C.E. Bush, ${ }^{3}$ M. Caorlin, Z. Chang, ${ }^{4}$ D.S. Darrow, H. Duong, 5 R. Durst, 4 P.C. Efthimion, D. Ernst, 6 R. Fisher, 5 R.J. Fonck, 4 E. Fredrickson, B. Grek, L.R. Grisham, G. Hammett, R.J. Hawryluk, W. Heidbrink, 7 H.W. Herrmann, K.W. Hill, J. Hosea, H. Hsuan, A. Janos, D.L. Jassby, F.C. Jobes, D.W. Johnson, L.C. Johnson, H. Kugel, N.T. Lam, ${ }^{4}$ B. LeBlanc, F.M. Levinton, 2 J. Machuzak, 6 D.K. Mansfield, E. Mazzucato, R. Majeski, E. Marmar, ${ }^{6}$ J. McChesney, ${ }^{5}$ K.M. McGuire, G. McKee, 4 D.M. Meade, S.S. Medley, D.R. Mikkelsen, D. Mueller, M. Murakami, 3 R. Nazikian, M. Osakabe, 8 D.K. Owens, H. Park, S.F. Paul, M. Petrov, 9 C.K. Phillips, A.T. Ramsey, M.H. Redi, D. Roberts, ${ }^{4}$ J. Rogers, A.L. Roquemore, E. Ruskov, ${ }^{7}$ S.A. Sabbagh, ${ }^{10}$ M. Sasao, ${ }^{8}$ G. Schilling, J. Schivell, G.L. Schmidt, S.D.Scott, C.H. Skinner, J.A. Snipes, ${ }^{6}$ J. Stevens, T. Stevensom, B.C. Stratton, E. Synakowski, G. Taylor, J.L. Terry, 6

A. von Halle, S. von Goeler, J.B.Wilgen, ${ }^{3}$ J.R. Wilson, K.L. Wong, G.A. Wurden, ${ }^{1}$ M. Yamada, K.M. Young, M.C. Zamstorff, and S.J. Zweben

Princeton Plasma Physics Laboratory, P.O. Box 451, Princeton, NJ 08543

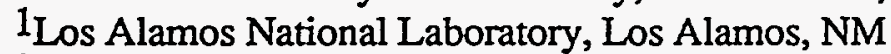

2Fusion Physics and Technology, Torrance, CA

3 Oak Ridge National Laboratory, Oak Ridge, TN

4University of Wisconsin, Madison, WI

5 General Atomics, San Diego, CA

6 Massachusetts Institute of Technology, Cambridge, MA

7 University of California, Irvine, CA

8 National Institute for Fusion Science, Nagoya, Japan

9Ioffe Physical-Technical Institute, Russia

${ }^{10}$ Columbia University, New York, $N Y$

\begin{abstract}
.
Three initial campaigns to increase the fusion power in DT plasmas on the Tokamak Fusion Test Reactor [TFTR] prior to July 1994 are described. The first campaign was dedicated to obtaining $>5 \mathrm{MW}$ of fusion power while avoiding MHD events similar to the JET X-event. The second was aimed at producing maximum fusion power irrespective of proximity to MHD limits, and achieved $9 \mathrm{MW}$ limited by a disruption. The third campaign increased the energy confinement time using lithium pellet conditioning with the hope of increasing the ratio of alpha heating to beam heating.
\end{abstract}

\section{Introduction}

TFTR commenced tritium operation in November 1993[1,2] and produced 182 plasmas containing some amount of tritium by June 1994. A major element of this initial operational 
period was to determine the DT fusion power level which can be achieved in TFTR. A fusion power output of 6.2 MW was attained in December 1993 and 9.2 MW in May 1994. Similarly prepared plasmas were subsequently replicated in reproducible scans to study tritium isotope effects[3] and expected alpha-particle driven instabilities. Analysis of these effects are reported in other papers at this conference and in future publications. The primary purpose of this paper will be to describe the campaigns at raising the fusion power and the issues that are important for this goal.

The main challenge to maximizing fusion power production is dealing with several important problems in tokamak research simultaneously: the plasma must operate at high energy confinement, with high neutral beam power, and low impurity influx from the limiter and walls. In addition, the plasma cannot be too close to stability limits, otherwise variations in confinement due to MHD might be inadvertently interpreted as alpha and tritium phenomena. Moreover, since the expected alpha particle heating and isotope effects are modest in magnitude, high reproducibility of plasma conditions is required to allow the isotope scaling and alpha heating to be identified separately. This was accomplished by comparing performance in pure deuterium, pure tritium and 50:50 DT plasmas. Of course, the desired plasma conditions must be obtained on the specific (and still fairly rare) plasmas that tritium is used, so that the plasma performance must be predictable. Finally, the highest fusion power is obtained with the highest beam power, highest confinement, lowest impurity influx, and best stability, so that the most extreme conditions must also be obtained in DT.

The most striking feature of the campaign to raise the fusion power has been that in the course of optimizing the energy confinement time through lithium gettering[4], the confinement rose so much that the supershot regime in TFTR is no longer confinement limited but is stability limited. That is, TFTR cannot operate at maximum plasma current and toroidal magnetic field with maximum beam power and the maximum achievable confinement time without encountering high $\beta$ disruptions.

\section{Experimental Campaigns}

TFTR operated at $\mathrm{R} / \mathrm{a}=2.52 \mathrm{~m} / 0.87 \mathrm{~m}, 5.1 \mathrm{~T}$ toroidal magnetic field with neutral beam heating in three different campaigns to produce high fusion power which are illustrated in Fig. 1. The three campaigns were:

\subsection{December 1993 Campaign}

In December 1993, $\mathrm{I}_{\mathrm{p}}=2.0 \mathrm{MA}$, and $\mathrm{PB}=29 \mathrm{MW}$ was used in a campaign to obtain greater than 5 MW of fusion power. The machine parameters were selected to avoid a minor disruption which on TFTR would appear similar to the JET X-event. Since the X-event had occurred on both JET tritium plasmas[5], we wanted to be certain that our deuterium set-up plasmas had very little probability of a minor disruption. We did not want an inadvertent minor disruption on a DT plasma being attributed to either the presence of tritium or fusion-product alpha particles. Essentially, this required operating the experiment at less than full beam power ( $29.5 \mathrm{MW}$ out of a potential $37 \mathrm{MW}$ ) and at less than the optimum energy confinement time. The confinement time was kept low by not using lithium pellet conditioning. The result was that 42 deuterium 
comparison plasmas were performed with only six having minor distuptions while none of the trace tritium, 50:50 DT, or full tritium plasmas had a minor disruption.

A consequence of this experiment was that an excellent set of DD to DT comparison plasmas was obtained in which the key parameters known to affect energy confinement and neutron emission in supershot plasmas were held constant, including the beam power, the balance of beam power in the co-direction, the plasma current, and the degree of wall conditioning (as expressed empirically by the carbon influx at the beginning of the beam injection). The parameters obtained in this campaign (Table 1) consistently indicated that the DT plasmas have better performance than the DD plasmas. An analysis of these differences is being reported elsewhere [3]. Of considerable interest is that in TFTR, $n_{e}(0)$ and $T_{e}(0)$ are about one-half of those expected for an ignited ITER; $T_{i}(0)$ is about twice that expected for ITER; the calculated alpha density is about one-fifth of ITER; and the fraction of the electron density due to alphas is about one-half that of ITER. This motivates our campaigns to increase fusion power on TFTR, to make the beta alpha more relevant to an ignited plasma. Evidently, ignition as envisioned by the ITER device is quite similar to the TFTR central plasma. The principal difference is that the conduction losses (dependent on the gradient scale length) are much smaller in ITER than in TFTR due to the large size of ITER.

Another interesting feature in Table 1 is that JET and TFTR had opposite trends in going from DD comparison plasmas to DT plasmas. JET experienced reduced $\tau_{E}, T_{e}(0), n_{e}(0)$, increased $Z_{\text {eff }}$ and constant $T_{i}$ with the addition of tritium, while TFTR experienced increased $\mathrm{T}_{\mathrm{e}}(0), \mathrm{T}_{\mathrm{i}}(\mathrm{o})$, and $\tau_{\mathrm{E}}$, while $\mathrm{Z}_{\mathrm{eff}}$ and $\mathrm{n}_{\mathrm{e}}(0)$ remaining about constant. The trend in the TFTR variations has been consistent for all TFTR DT experiments with comparable limiter conditioning.

\subsection{May 1994 Campaign}

The second campaign occurred in May 1994 using $I_{p}=2.5 \mathrm{MA}, \mathrm{PB}$ up to $33 \mathrm{MW}$, and up to two lithium pellets (about $1 \mathrm{sec}$. before neutral beam injection) to improve the plasma confinement. The plasma current was chosen as the maximum available (with a reasonable flattop time) in order to maximize the Troyon $\beta$ limit and allow the maximum energy content in the plasma. The intention was to apply the.maximum neutral beam power; however, minor and major disruptions occurred with about $33 \mathrm{MW}$ of beam power (11 out of 12 sources). Effectively, the plasma performance is limited by the disruptive behavior at the highest injected beam powers.

The campaign in May 1994 was remarkable for the effect that the lithium pellet conditioning had upon the energy confinement time during the beam heating. The previous best TFTR confinement time at $2.5 \mathrm{MW}$ had been about $0.11 \mathrm{sec}$ (at time of peak neutron emission) (Fig. 2) which was modestly above L-mode. At the beginning of the campaign, even without lithium pellet injection, the confinement time was about $0.15 \mathrm{sec}$. This increase is presently interpreted as a conditioning effect from the proceeding experiment which featured heavy lithium pellet conditioning. Sequentially, as first one lithium pellet was added prior to beam injection, then two lithium pellets were added, and finally two lithium pellets were added as well as an ohmic preconditioning plasma (at $1.6 \mathrm{MA}$ with $4 \mathrm{Li}$ pellets), the confinement time rose steadily to be about $0.2 \mathrm{sec}$ or nearly twice as high as in July 1993. With the DT plasma operation and 1 or $2 \mathrm{Li}$ pellets before the beam injection, the isotope effect brought the confinement time up to $0.24 \mathrm{sec}$ or nearly tripling the confinement over L-mode. The strong control that the lithium pellet 
conditioning brings to the confinement time means that TFTR is effectively stability-limited rather than confinement limited.

The May 1994 sequence of DD plasmas in Fig. 2 were all taken at $19.5 \mathrm{MW}$ of beam power and illustrate (Fig. 3) the pronounced effect that the lithium conditioning had upon the density profile, and particle influxes during the beam injection. At about $3.9 \mathrm{sec}$, the hydrogen influx and carbon influxes were halved while the central density was about constant (or increased by $10 \%$ ); the density peakedness was increased by about $50 \%$ as the energy confinement time increased about $30 \%$.

The general observations are consistent with previous measurements of the effects of lithium pellets [4] except that they seem more pronounced at the higher plasma current (2.5 MA) of this campaign. Higher plasma current also correlates with higher particles influxes from the walls, especially during ohmic heating. Qualitatively, the lithium gettering seems to be effective at reducing the higher particle influx at higher plasma current. Historically, improvements in supershot performance in TFTR has involved a deterioration at higher plasma currents. Initially (in 1986), supershots were most effective at low plasma current ( $1.0 \mathrm{MA})$, and over the years improvements over L-mode in performance meant considerable enhancements, were extended to higher plasma currents. The maximum current that can sustain $\tau_{\mathrm{E}}>1.8 \tau_{\mathrm{E}}^{\mathrm{L} \text {-mode }}$ has increased (Fig. 4) from 1.0 MA in 1986 to 2.5 MA in 1994.

\subsection{June 1994 Campaign}

The third campaign occurred in June 1994 using $I_{p}=2.1 \mathrm{MA}, \mathrm{PB} \sim 20 \mathrm{MW}$ and four $\mathrm{Li}$ pellets at least $1 \mathrm{sec}$ before neutral beam injection. In this campaign, the plasma current was chosen as the maximum that allowed enough time for the four lithium pellets to be injected. The beam power was reduced sufficiently to avoid approaching $\beta$ limits. The consequence was that approximately the same DT fusion power was produced as in December 1993 but with about twothirds of the beam heating power. The peak energy confinement time achieved was about $0.28 \mathrm{sec}$.

There are several significant features about the profiles (Fig. 5) produced at the highest confinement times. Compared to the July 1993 plasma (Fig. 2), there are significant reductions in $\mathrm{D}_{\mathrm{e}}, \chi_{\mathrm{e}}$, and $\chi_{\mathrm{i}}$ with associated increases in $\mathrm{n}_{\mathrm{e}}(0), \mathrm{T}_{\mathrm{e}}(0)$, and $\mathrm{T}_{\mathrm{i}}(0)$. At the time of the highest confinement, the central $T_{i}$ actually became flat over the inner $r / a<0.25$ at a value of about 35 $\mathrm{keV}$, and the ion energy balance became convection dominated (Fig. 6). The initial impression is that the increases in $\tau_{\mathrm{E}}$ due to $\mathrm{Li}$ pellet conditioning are accompanied by a broadening flat $\mathrm{T}_{\mathrm{i}}(\mathrm{r})$ as the central region dominated by convective losses becomes broader. Similar observations have been made previously on supershot behavior[6]; however, the June 1994 plasmas seem to have the most extreme effect.

\section{Fusion Power Production}

Empirically, the D(d,n) ${ }^{3} \mathrm{He}$ fusion neutron emission from TFTR supershots has scaled[7] as

$$
S_{D D} \propto E^{2} / \sqrt{I_{p}}
$$


which can be seen with respect to the 1990 data as having a tight correlation (Fig. 7). Empirically, the DT data in which the fraction of tritium beam power lies between $30 \%$ and $70 \%$ of the total also follows a similar scaling relation with (Fig. 8)

$$
S_{D T} \propto E^{1.8} / \sqrt{I_{p}}
$$

The $I_{p}$ variation is not over a wide range and represents only the difference between data at $1.8 \rightarrow$ $2.1 \mathrm{MA}$ versus data at 2.5 MA (Fig. 9). The scalings [Eq. (2)] of the DT plasmas is quite similar to the scaling of the DD [Eq. (1)] plasmas indicating that optimization of the deuterium plasmas for DD neutron emission is a valid indicator of expected DT neutron performance. Further, the strong dependence upon plasma energy content indicates that the relevant parameters for improving the DT fusion power are the product of the energy confinement time and the applied neutral beam heating power. Plotting the 1990 and $1992 \mathrm{DD}$ supershot data (over 1,000 plasmas) in $\tau_{\mathrm{E}}, \mathrm{PB}_{\mathrm{B}}$ space indicates (Fig. 10) that DD data tended to evenly fill a space below $32 \mathrm{MW}$ and $160 \mathrm{msec}$ confinement time. The DT plasmas form bands of fusion power along contours of constant plasma energy content irrespective of whether that energy content is obtained at high applied beam power or high energy confinement time.

The DT neutron production plotted as a function of the percentage of the beam sources that are used in tritium (Fig. 11) has a broad maximum around $50 \%$. The plasmas with only tritium beams injected have $40-60 \%$ of the DT neutron emission expected from Eq. (2). The fact that they have any DT neutron emission is due to the deuterium influx from the walls where a large reservoir has been established from many DD plasmas. Figure 11 indicates little further benefit exists to operating slightly rich in tritium beyond the effect of maximizing the plasma energy content. Since TFTR is now ultimately limited by stability, it is not clear which beam configuration nor tritium configuration in the beams would allow the maximum $\beta$ to be obtained without disruption.

\section{Summary}

The dramatic effect of lithium pellet conditioning and the tritium isotope effect upon energy confinement time has changed the overall TFTR machine performance from being limited by confinement to being limited by stability. In order to further increase the peak DT fusion power and to extend the duration of high DT fusion power for alpha studies, it is proposed to increase the toroidal magnetic field from 5.2 T to $6 \mathrm{~T}$. Empirically, it has been observed that the maximum DD neutron emission scales with the fourth power of the toroidal magnetic field (Fig. 12). This is understandable from a scaling law like Eq. (1) where the maximum attainable energy content is determined by a Troyon-like energy limit

$$
E_{\text {Troyon }} \propto I B \propto B^{2} / q
$$

and somehow $\mathrm{q}$ is being held constant so that

$$
S_{D D_{\max }} \propto B^{4} .
$$


The fact that $\mathrm{q} \cong$ constant may be a consequence of the high central pressures in TFTR supershots suggesting that the $q=1$ surface is important, or that the $q$ on axis is important (i.e., central current density). The empirical data in Fig. 12 indicates that an approximate doubling of the DT fusion power may be possible by raising the toroidal magnetic field from $5 \mathrm{~T}$ to $6 \mathrm{~T}$.

\section{Acknowledgment}

This work was supported by the U.S. Department of Energy Contract No. DE-AC02-76-CHO3073. 


\section{Parameters for DD and DT comparison plasmas}

\begin{tabular}{|c|c|c|c|c|c|}
\hline Parameter & JET DI) & JET DT & TFTR DD & TFTRD-T & ITER \\
\hline Central density $\mathrm{n}_{\mathrm{e}}(0) 10^{19} \mathrm{~m}^{-3}$ & 5.1 & 3.6 & 7.7 & 7.6 & 16 \\
\hline Effective charge (Zeff) & 1.8 & 2.4 & 2.4 & 2.3 & 1.5 \\
\hline $\begin{array}{l}\text { Electron temperature keV } \\
\mathrm{T}_{e}(0)\end{array}$ & 10.5 & 9.9 & 9.2 & 10.8 & 18 \\
\hline Ion temperature $T_{i}(0) \mathrm{keV}$ & 18.6 & 18.8 & 25.6 & $\mathbf{3 3 . 0}$ & 17 \\
\hline $\begin{array}{l}\text { Energy replacement seconds } \\
\text { Time }\left(\tau_{E}\right)\end{array}$ & 1.2 & 0.9 & 0.145 & 0.176 & 4.1 \\
\hline Central alpha density $1019 \mathrm{~m}-3$ & 0 & 0.0029 & 0 & 0.013 & 0.08 \\
\hline$R \nabla \beta \alpha$ & 0 & 0.008 & 0 & 0.02 & 0.06 \\
\hline$\left(1020 \mathrm{~m}-3_{\mathrm{sec} \mathrm{keV}}\right)$ & 4.6 & 2.9 & 2.6 & 3.8 & 35 \\
\hline
\end{tabular}

\section{References}

[1] R. J. Hawryluk, et al., Phys. Rev. Lett. 72 (1994) 3530.

[2] J. D. Strachan, et al. Phys. Rev. Lett. 72 (1194) 3526.

[3] S. D. Scott, D. R. Ernst, M. Murkamai, H. Adler, Cris W. Barnes et al., "Isotopic scaling of transport in deuterium-tritium plasmas", presented at Workshop on Transport in Fusion Plasmas, Goteborg, Sweden, June 1994. Submitted to Physica Scripta.

[4] J. Snipes, et al., Proc. of European Conf. on Pl. Phys. and Contr. Fusion (Berlin, 1991) Part III p. 141.

[5] The JET Team, Nuclear Fusion 32, 187 (1992).

[6] M.C. Zarnstorff, M.G. Bell, M. Bitter, C. Bush, R.J. Fonck et al., "Convective Heat Transport in TFTR Supershots", Proceedings of the 15th European Conference on Controlled Fusion and Plasma Physics, Dubrovnik, 1988, Vol. 1, 1988, (European Physical Society, Petit-Lancy, Switzerland), p. 95-98. 
[7] J. D. Strachan, et al, Nuclear Fusion $\underline{33}, 991$ (1993). 


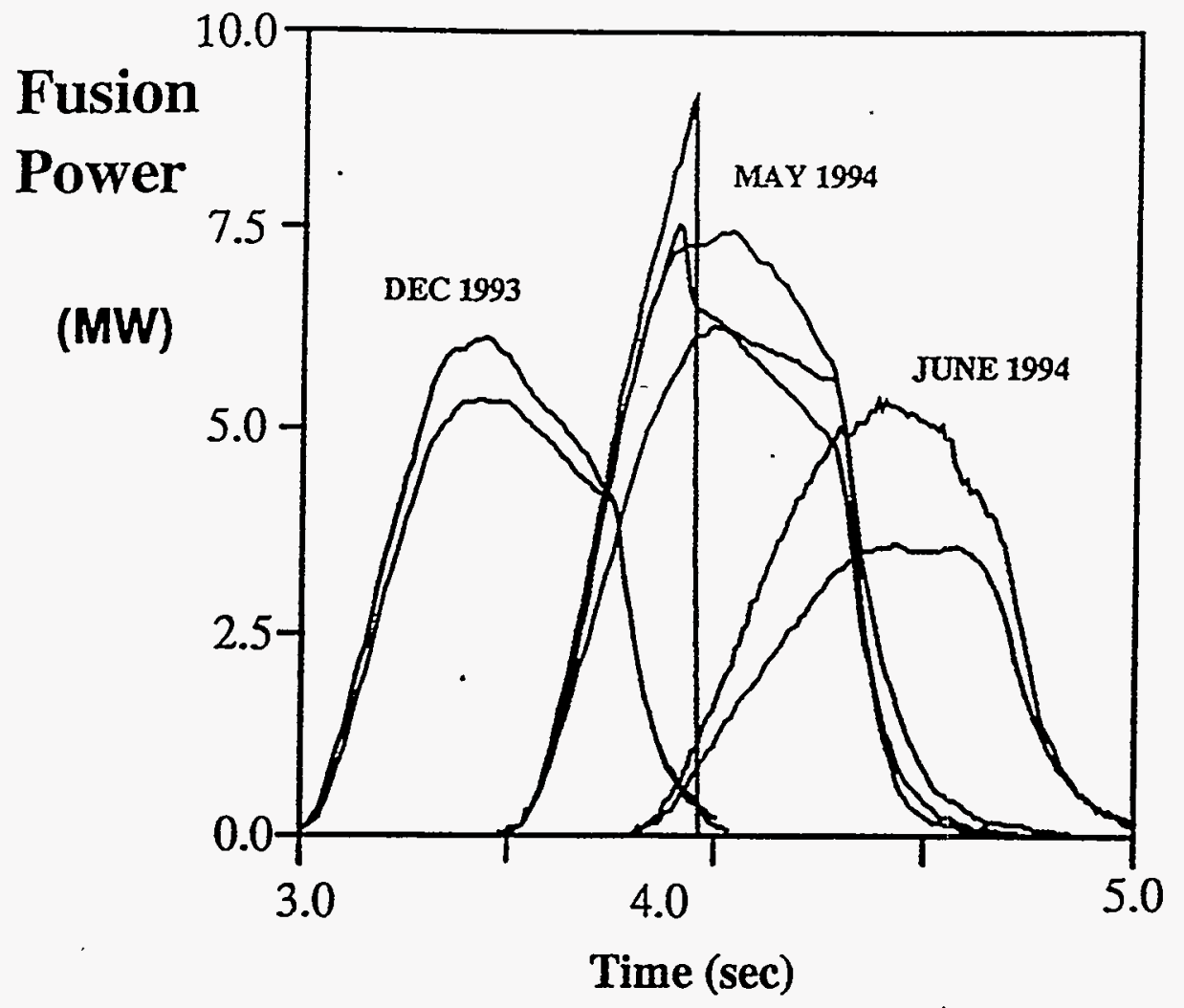

Fig. 1 Time evolution of the DT fusion power produced during the three campaigns to increase the TFTR fusion power. 


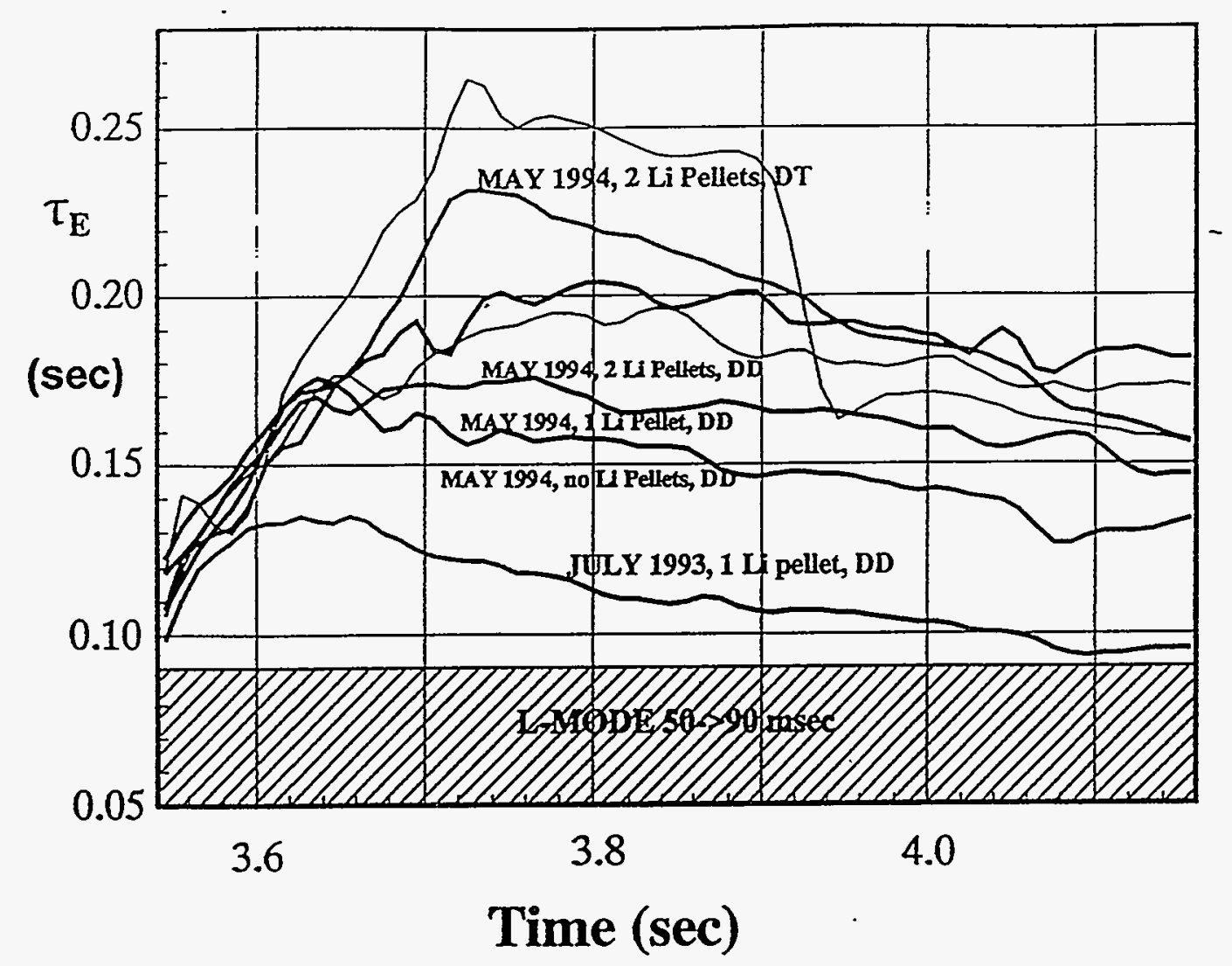

Fig. 2. Time evolution of the energy confinement time for $2.5 \mathrm{MA}$ beam heated TFTR plasmas. The range of L-mode energy confinement is indicated in the shaded region and depends upon the beam power. The bottom curve represents the best TFTR performance at 2.5 MA up to July 1993. The next four curves represent the effect of lithium pellet conditioning of DD plasmas as part of the May 1994 campaign. The top two curves represent the effect of lithium pellet conditioning of DT plasmas. 
$-76653-76651$ man $76650 \cdots 76649$
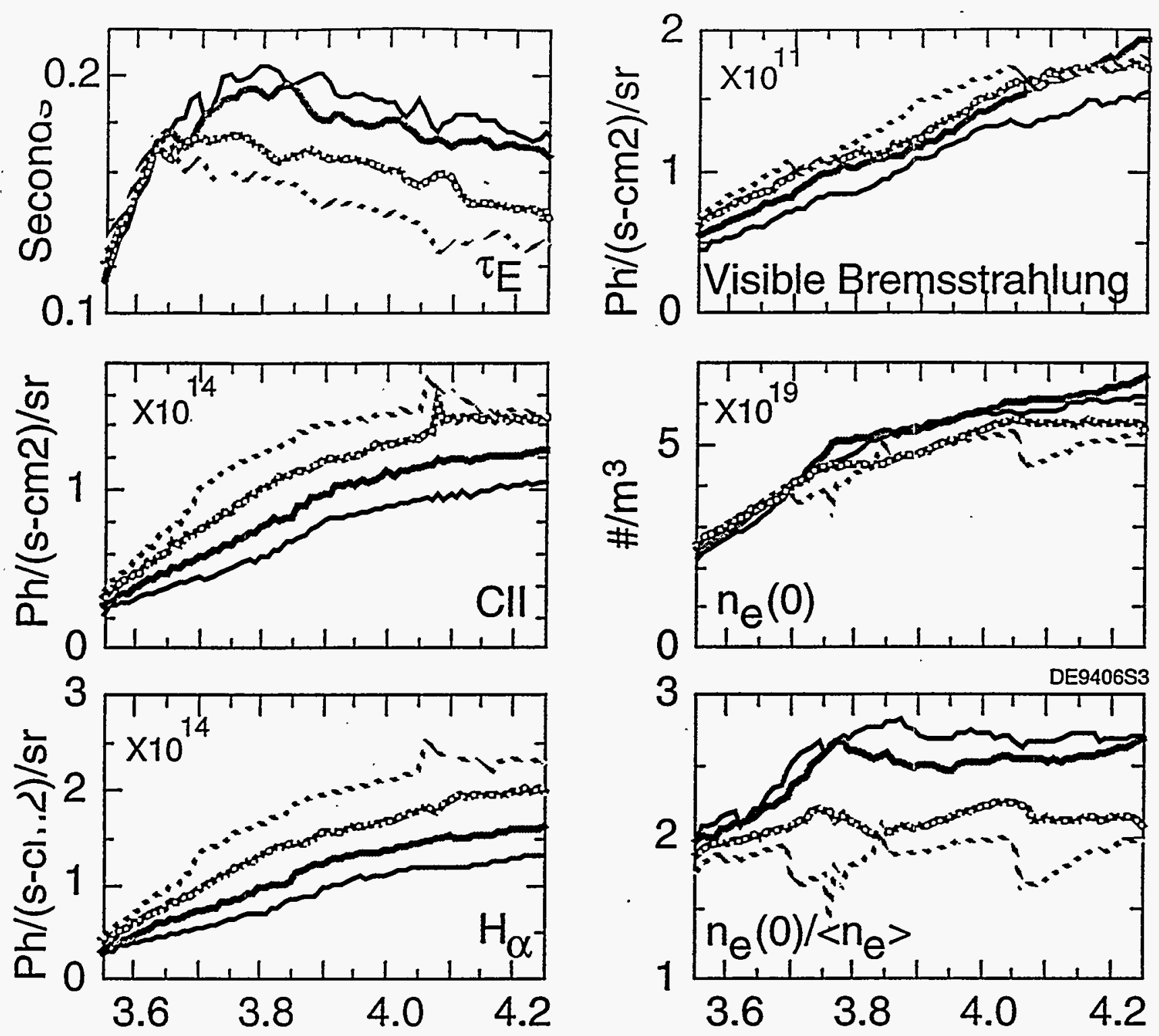

\section{Time $(\mathrm{Sec})$}

Fig. 3 Time evolution of four plasmas each having 19.5 MW of beam heating. 76649 had no lithium pellets, 76650 had one Li pellet about $1 \mathrm{sec}$ before beam injection, 76651 had two $\mathrm{Li}$ pellets about $1 \mathrm{sec}$ before beam injection and 76653 had two Li pellets prior to beam injection and was preceded by a four Li pellet ohmic (pre-conditioning) shot. The data are, energy confinement time, visible bremsstrahlung emission, $\mathrm{H}_{\alpha}$ light-hydrogen flux, CII light-carbon influx, central electron density, and density peakedness $\left.n_{e}(0) /<n_{e}\right\rangle$. 


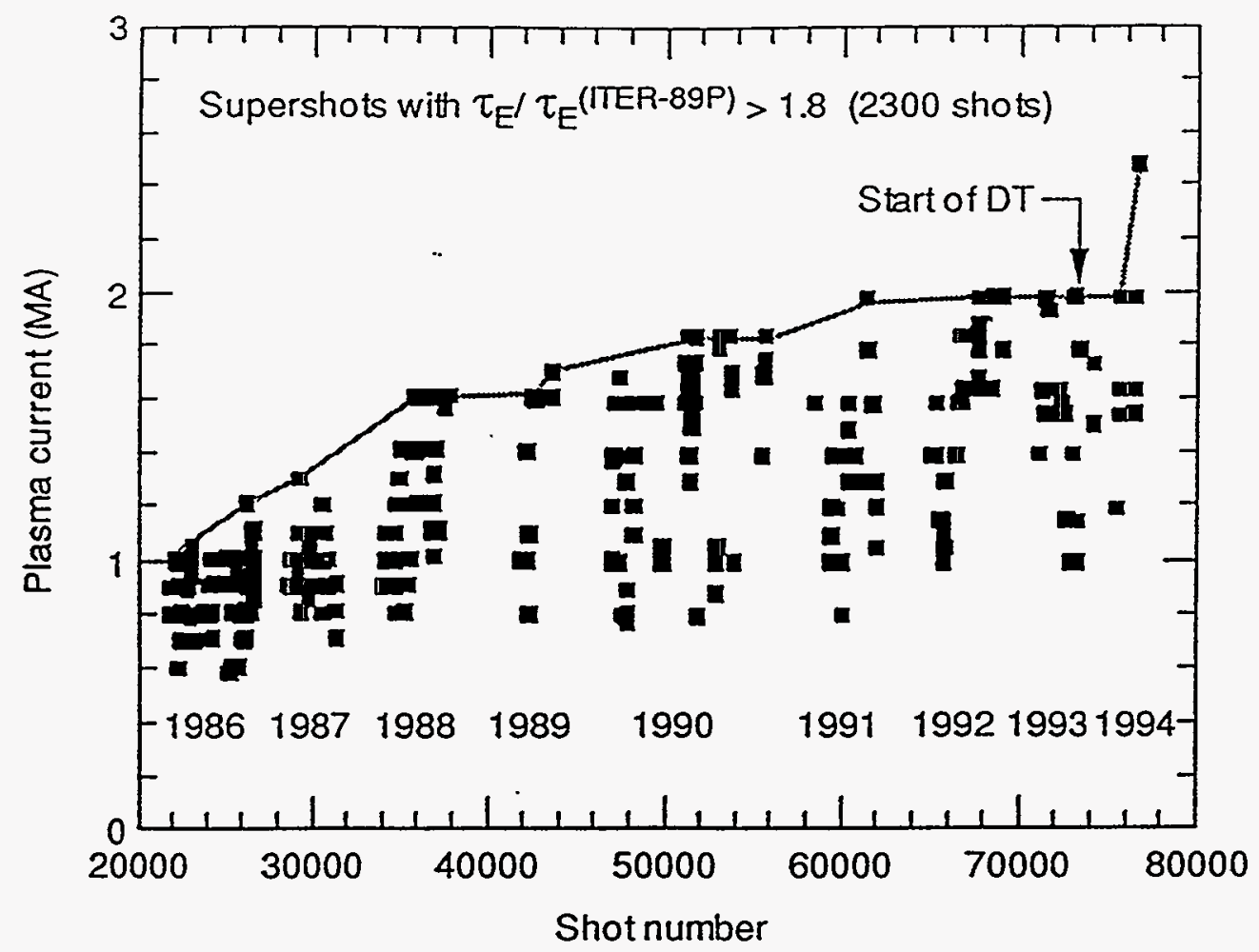

Fig. 4 The evolution of plasma current of TFTR plasmas having $\tau_{\mathrm{E}}>1.8 \tau_{\mathrm{L} \text {-mode }} 1.8$ is the mean enhancement of all TFTR supershots over L-mode. 

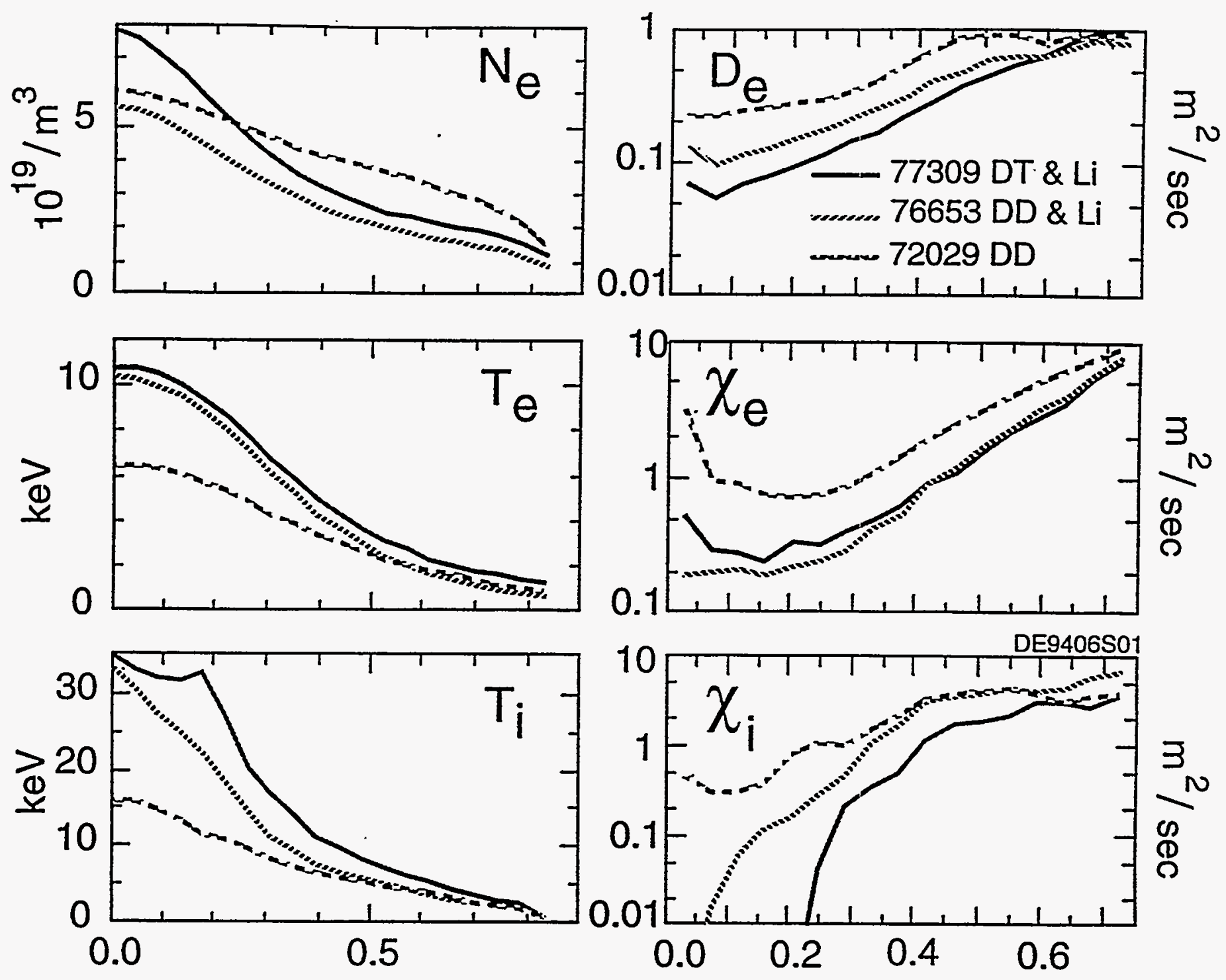

Minor Radius (m)

Fig. 5 The $n_{e}(r), T_{e}(r)$, and $T_{i}(r)$ profiles with the deduced $D_{e}(r), \chi_{e}(r)$, and $\chi_{i}(r)$ profiles. The solid line is the best TFTR DT confinement time from the June 1994 campaign (2.1 MA, 20.5 MW DT), the long dashed line is the July 1993 plasma (Fig. 2) (2.5 MA, 30.5 MW, $\mathrm{DD})$, the short dashed line is the top DD data point in Fig. 2 from the May 1994 campaign (2.5 MA, 19.5 MW, DD). 


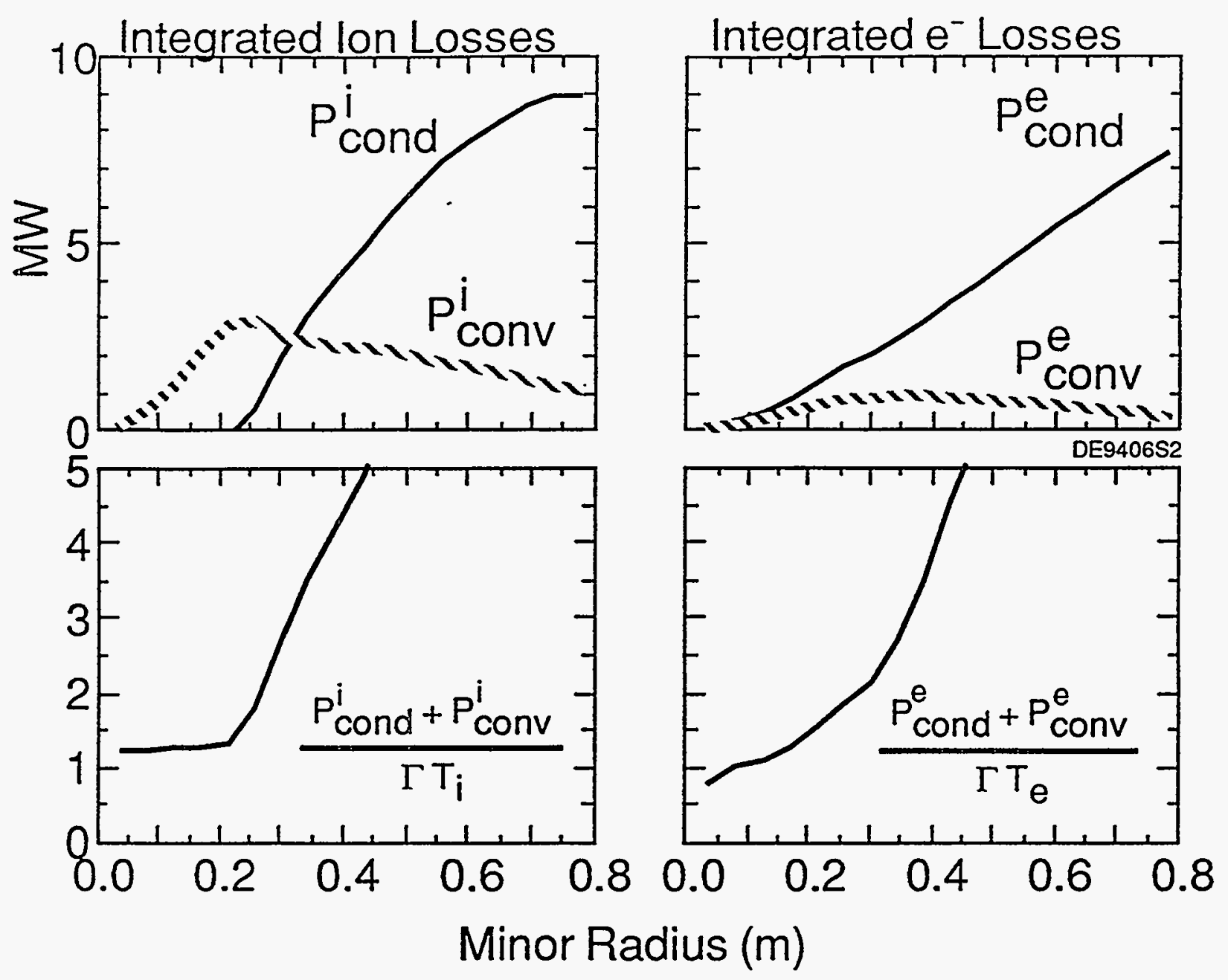

Fig. 6 The radial dependence of the conduction and convection terms in the energy balance near the time of peak energy confinement time. The ratio of the convective ion energy loss to the particle flux indicates that a $3 / 2$ convective multiplier is appropriate. 


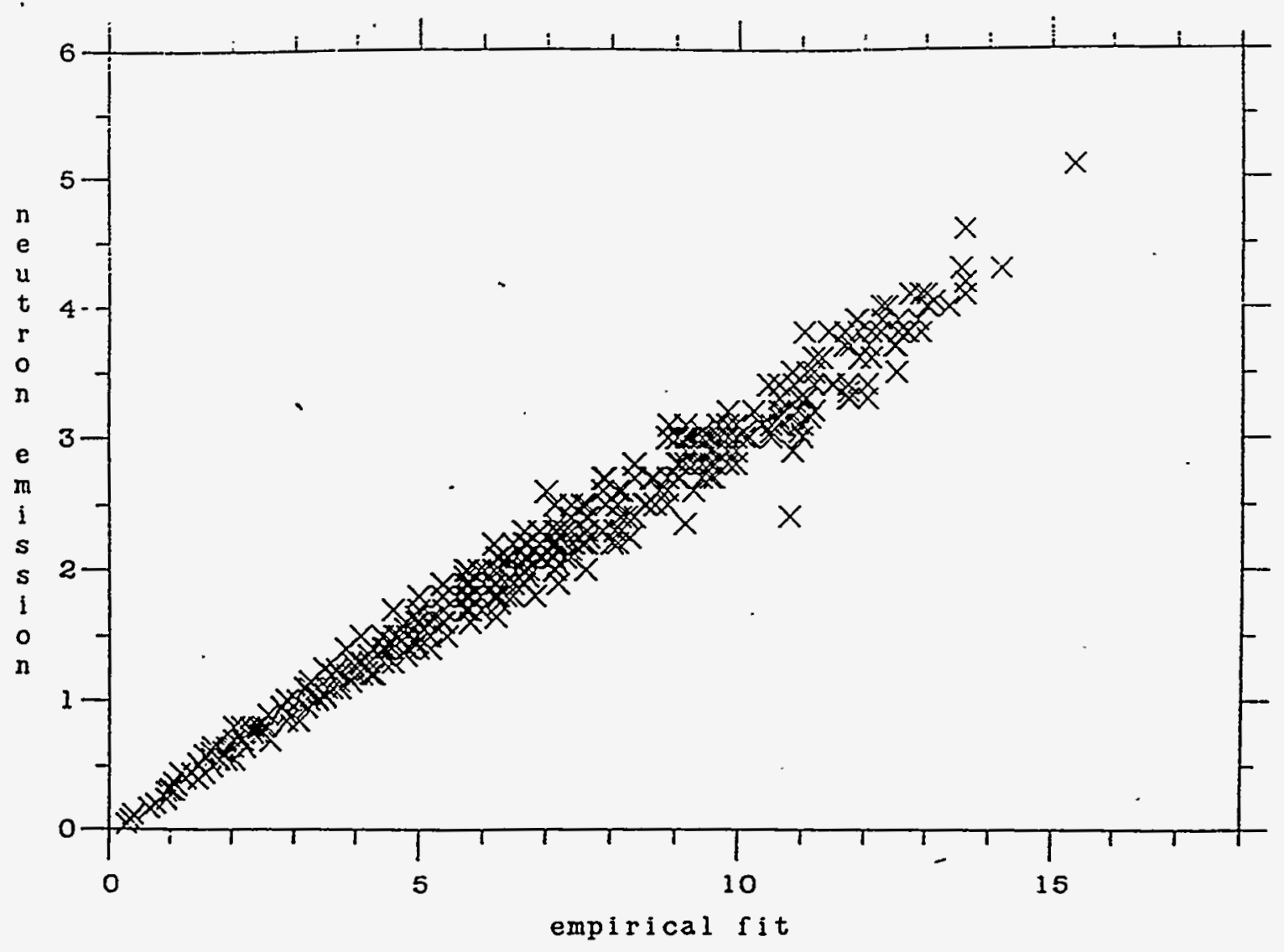

Fig. 7 The DD fusion neutron rate from the 1990 TFTR data set plotted against the empirical scaling relation $\mathrm{E}^{2} / \mathrm{II}_{\mathrm{p}}$. 


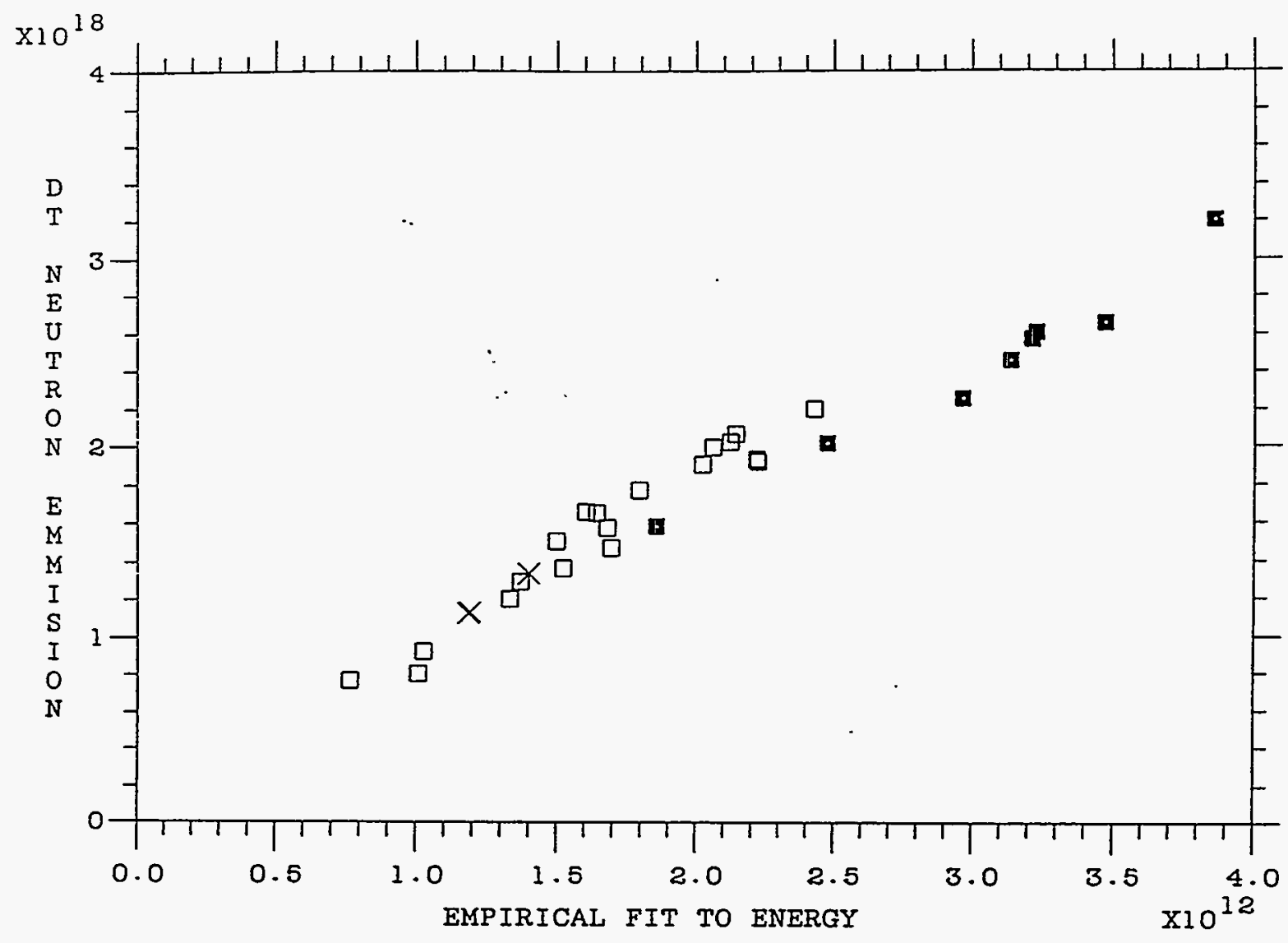

Fig. 8 The DT fusion power production from the DT plasmas with the fraction of tritium sources between 0.3 and 0.7 plotted against the empirical scaling relation $E 1.8$. The $X$ points are at 1.8 MA, the open squares are at 2.0 or $2.1 \mathrm{MA}$ and the solid squares are at 


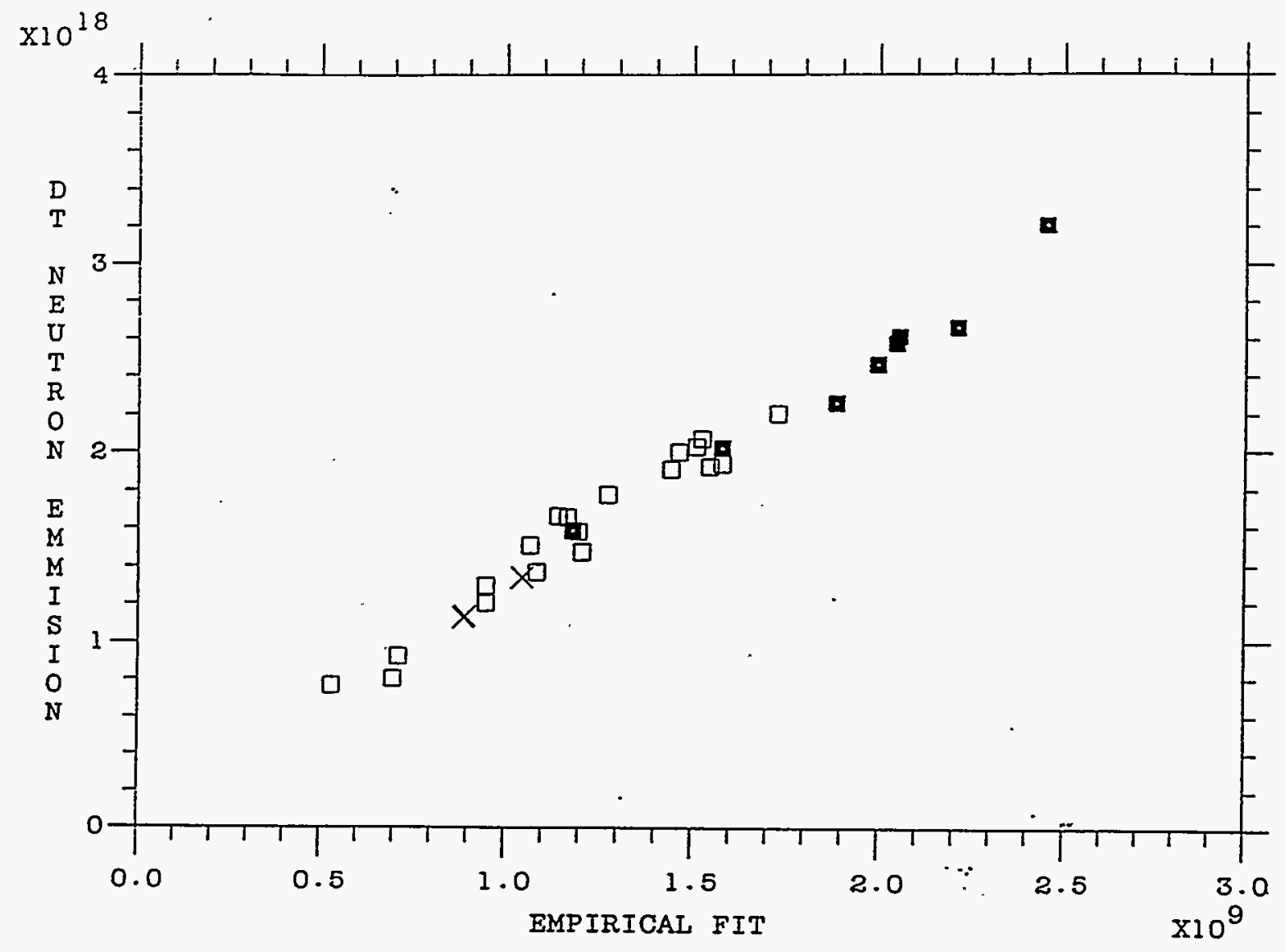

Fig. 9 The DT fusion power production for the data in Fig. 8 plotted against the empirical scaling relation $\mathrm{E} 1.8 / \mathrm{N} \mathrm{I}_{\mathrm{p}}$. 


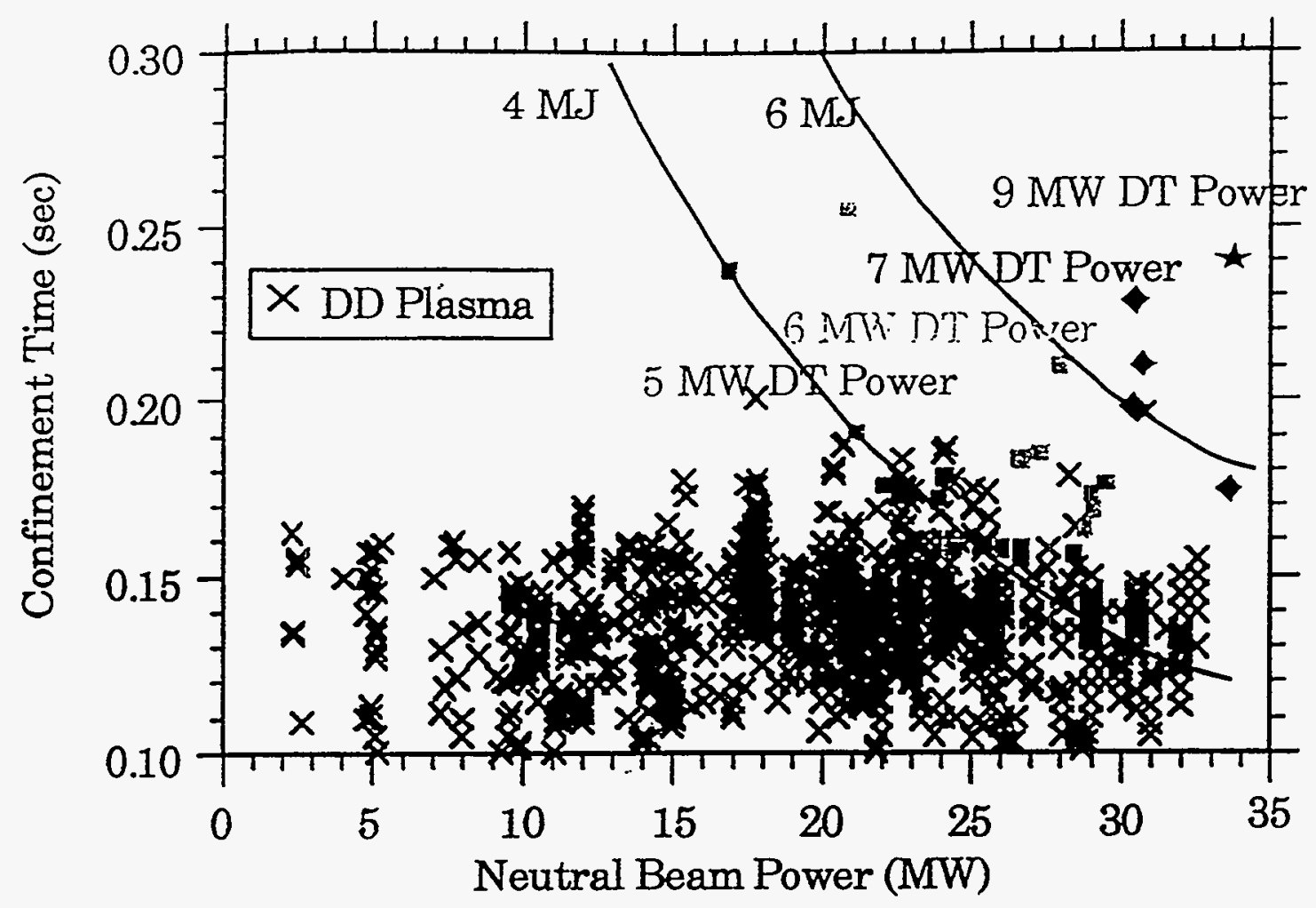

Fig. 10 The energy confinement time (at time of peak neutron emission) plotted against the applied neutral beam power. The X points are the DD data from 1990 and 1992 (over 1,000 plasmas). The remaining symbols represent DT plasmas having different fusion power $3.5-5.0 \mathrm{MW}$ is open squares, $5.0-6.5 \mathrm{MW}$ is solid squares, $6.5-8.0 \mathrm{MW}$ is the diamonds, and $9.2 \mathrm{MW}$ is the star. The lines are constant energy content. 


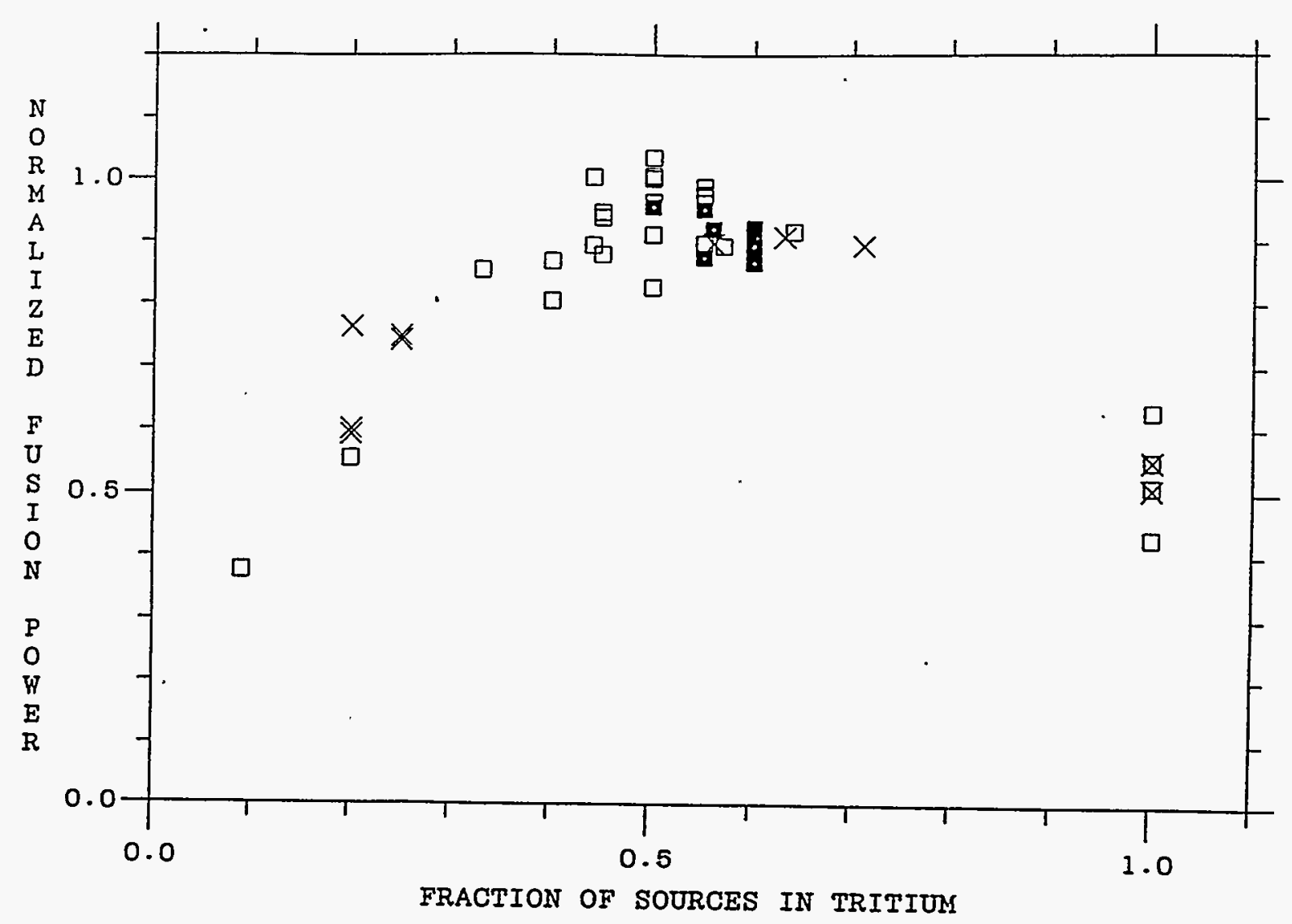

Fig. 11 The DT fusion power divided by the empirical scaling law [Eq. (2)] plotted as a function of the fraction of beam power in tritium. 


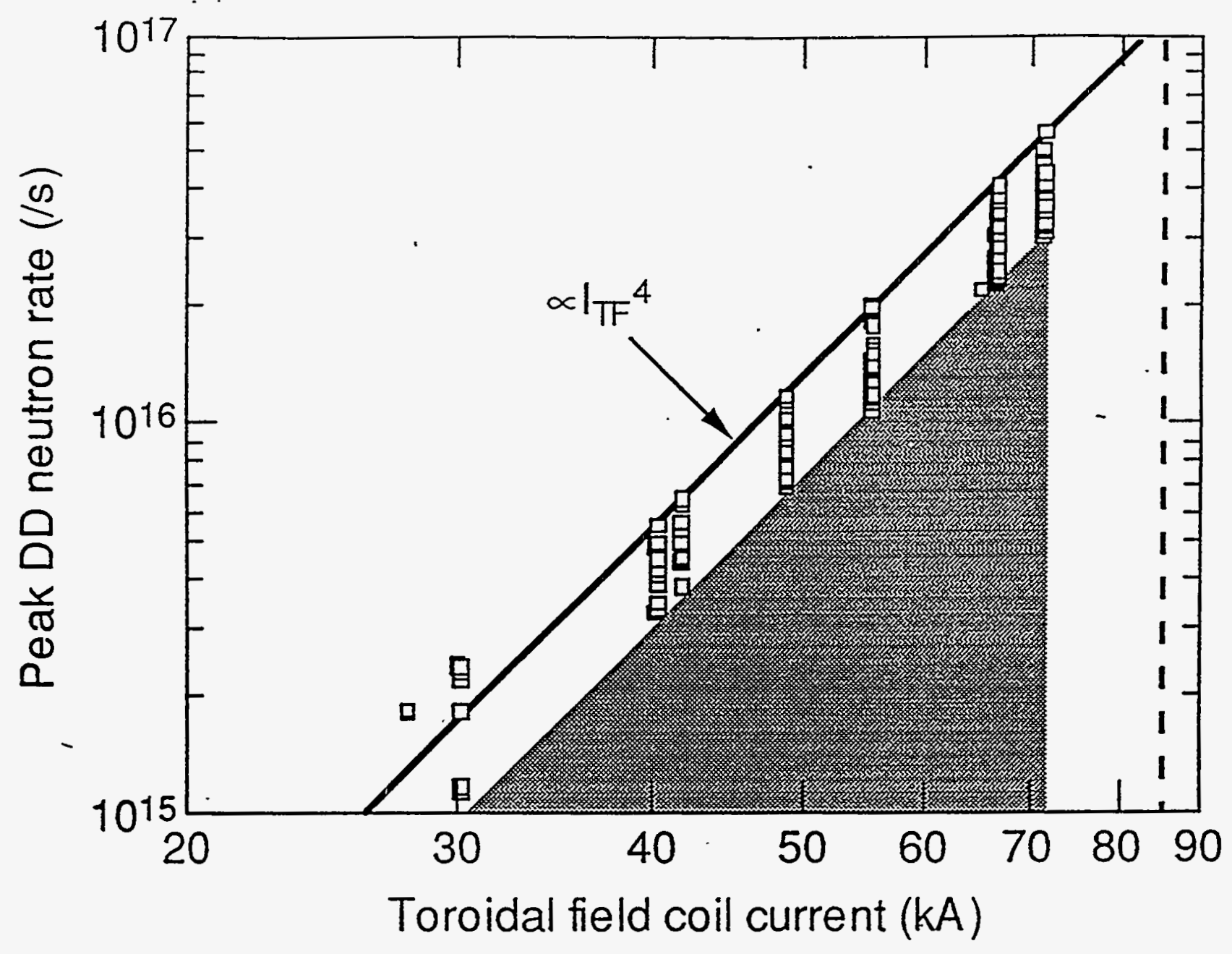

Fig. 12 The DD neutron emission plotted as a function of the current in the TFTR toroidal magnetic field coils. 


\section{EXTERNAL DISTRIBUTION IN ADDITION TO UC-420}

Dr. F. Paoloni, Univ. of Wollongong, AUSTRALIA

Prof. R.C. Cross, Univ. of Sydney, AUSTRALIA

Plasma Research Lab., Australian Nat. Ùniv., AUSTRALIA

Prof. I.R. Jones, Flinders Univ, AUSTRALIA

Prof. F. Cap, Inst. for Theoretical Physics, AUSTRIA

Prof. M. Heindler, Institut for Theoretische Physik, AUSTRIA

Prof. M. Goossens, Astronomisch Instituut, BELGIUM

Ecole Royale Militaire, Lab. de Phy. Plasmas, BELGIUM

Commission-European, DG. XII-Fusion Prog., BELGIUM

Prof. R. Bouciqué, Rijksuniversiteit Gent, BELGIUM

Dr. P.H. Sakanaka, Instituto Fisica, BRAZIL

Prof. Dr. I.C. Nascimento, Instituto Fisica, Sao Paulo, BRAZIL Instituto Nacional De Pesquisas Espaciais-INPE, BRAZIL Documents Office, Atomic Energy of Canada Ltd., CANADA

Ms. M. Morin, CCFM/Tokamak de Varennes, CANADA

Dr. M.P. Bachynski, MPB Technologies, Inc., CANADA

Dr. H.M. Skarsgard, Univ. of Saskatchewan, CANADA

Prof. J. Teichmann, Univ. of Montreal, CANADA

Prof. S.R. Sreenivasan, Univ. of Calgary, CANADA

Prof. T.W. Johnston, INRS-Energie, CANADA

Dr. R. Bolton, Centre canadien de fusion magnétique, CANADA

Dr. C.R. James, Univ. of Alberta, CANADA

Dr. P. Lukác, Komenského Universzita, CZECHO-SLOVAKIA

The Librarian, Culham Laboratory, ENGLAND

Library, R61, Rutherford Appleton Laboratory, ENGLAND

Mrs. S.A. Hutchinson, JET Library, ENGLAND

Dr. S.C. Sharma, Univ. of South Pacific, FIJI ISLANDS

P. Măhơnen, Univ. of Helsinki, FINLAND

Prof. M.N. Bussac, Ecole Polytechnique,, FRANCE

C. Mouttet, Lab. de Physique des Milieux lonisés, FRANCE

J. Radet, CEN/CADARACHE - Bat 506, FRANCE

Prof. E. Economou, Univ. of Crete, GREECE.

Ms. C. Rinni, Univ. of loannina, GREECE

Preprint Library, Hungarian Academy of Sci., HUNGARY

Dr. B. DasGupta, Saha Inst. of Nuclear Physics, INDIA

Dr. P. Kaw, Inst. for Plasma Research, INDIA

Dr. P. Rosenau, Israol Inst. of Technology, ISRAEL

Librarian, Intemational Center for Theo Physics, ITALY

Miss C. De Palo, Associazione EURATOM-ENEA , ITALY

Dr. G. Grosso, Istituto di Fisica del Plasma, ITALY

Prof. G. Rostangni, Istituto Gas Ionizzati Del Cnr, ITALY
Dr. H. Yamato, Toshiba Res \& Devel Center, JAPAN

Prof. I. Kawakami, Hiroshima Univ., JAPAN

Prof. K. Nishikawa, Hiroshima Univ., JAPAN

Librarian, Naka Fusion Research Establishment, JAERI, JAPAN

Director, Japan Atomic Energy Research Inst., JAPAN

Prof. S. Itoh, Kyushu Univ., JAPAN

Research Info. Ctr., National Instit. for Fusion Science, JAPAN

Prof. S. Tanaka, Kyoto Univ., JAPAN

Library, Kyoto Univ., JAPAN

Prof. N. Inoue, Univ. of Tokyo, JAPAN

Secretary, Plasma Section, Electrotechnical Lab., JAPAN

Dr. O. Mitarai, Kumamoto Inst. of Technology, JAPAN

Dr. G.S. Lee, Korea Basic Sci. Ctr., KOREA

J. Hyeon-Sook, Korea Atomic Energy Research Inst., KOREA

D.I. Choi, The Korea Adv. Inst. of Sci. \& Tech., KOREA

Prof. B.S. Liley, Univ. of Waikato, NEW ZEALAND

Inst of Physics, Chinese Acad Sci PEOPLE'S REP. OF CHINA

Library, Inst. of Plasma Physies, PEOPLE'S REP. OF CHINA

Tsinghua Univ. Library, PEOPLE'S REPUBLIC OF CHINA

Z. Li, S.W. Inst Physics, PEOPLE'S REPUBLIC OF CHINA

Prol. J.A.C. Cabral, Instituto Superior Tecnico, PORTUGAL

Prof. M.A. Hellberg, Univ. of Natal, S. AFRICA

Prof. D.E. Kim, Pohang Inst. of Sci. \& Tech., SO. KOREA

Prof. C.I.E.M.A.T, Fusion Division Library, SPAIN

Dr. L. Stenflo, Univ. of UMEA, SWEDEN

Library, Royal Inst. of Technology, SWEDEN

Prof. H. Wilhelmson, Chalmers Univ. of Tech., SWEDEN

Centre Phys. Des Plasmas, Ecole Polytech, SWITZERLAND

Bibliotheek, Inst. Voor Plasma-Fysica, THE NETHERLANDS

Asst. Prof. Dr. S. Cakir, Middle East Tech. Univ., TURKEY

Dr. V.A. Glukhikh,Sci. Res. Inst. Electrophys.I Apparatus, USSR

Dr. D.D. Ryutov, Siberian Branch of Academy of Sci., USSR

Dr. G.A. Eliseev, I.V. Kurctatov Inst., USSR

Librarian, The Ukr.SSR Academy of Sciences, USSR

Dr. L.M. Kovrizhnykh, Inst. of General Physics, USSR

Kemforschungsanlage GmbH, Zentralbibliothek, W. GERMANY

Bibliothek, Inst. Fur Plasmaforschung, W. GERMANY

Prof. K. Schindler, Ruhr-Universitát Bochum, W. GERMANY

Dr. F. Wagner, (ASDEX), Max-Planck-Institut, W. GERMANY

Librarian, Max-Planck-Institut, W. GERMANY 